\title{
Optimization of novel melt-extruded polymer optical fibers designed for
}

\author{
pressure sensor applications
}

Brit M. Quandt, Rudolf Hufenus, Bernhard Weisse, Fabian Braun, Martin Wolf, Anke Scheel-Sailer, Gian-Luca Bona, René M. Rossi, Luciano F. Boesel*

Brit M. Quandt, Dr. Rudolf Hufenus, Bernhard Weisse, Prof. Dr. Gian-Luca Bona, Dr. René M. Rossi, Dr. Luciano F. Boesel

Empa, Swiss Federal Laboratories for Materials Science and Technology, Lerchenfeldstrasse 5, 9014 St. Gallen, Switzerland

E-mail: maike.quandt@empa.ch, luciano.boesel@empa.ch

Fabian Braun

CSEM, Swiss Center for Electronics and Microtechnology, Rue Jaquet-Droz 1, 2002

Neuchâtel, Switzerland

Prof. Dr. Martin Wolf

Biomedical Optics Research Laboratory, Dept. of Neonatology, University Hospital Zurich, Frauenklinikstrasse 10, 8091 Zurich, Switzerland

Dr. med. Anke Scheel-Sailer

Swiss Paraplegic Center, Guido A. Zäch Strasse 1, 6207 Nottwil, Switzerland

Brit M. Quandt, Prof. Dr. Gian-Luca Bona

ETH Zurich, Swiss Federal Institute of Technology, Department of Information Technology and Electrical Engineering, Gloriastrasse 35, 8092 Zurich, Switzerland

This document is the accepted manuscript version of the following article: Quandt, B. M., Hufenus, R., Weisse, B., Braun, F., Wolf, M. , Schee1-Sailerd, A., ... Boese1, L. F. (2017). Optimization of novel melt-extruded polymer optical fibers designed for pressure sensor applications. European Polymer Journal, 88, 44-55. https:// doi .org/10.1016/j.eurpolymj.2016.12.032

This manuscript version is made available under the CC-BY-NC-ND 4.0 1icense http://creativecommons.org/1icenses/by-nc-nd/4.0 


\begin{abstract}
We report on the production, characterization, and textile integration of polymer optical fibers (POF) to develop a flexible photonic sensor. Mono-component POFs were produced continuously by melt-extrusion. Advantageously for pressure sensing, the un-clad fibers are more susceptible to macro-bending.

The fibers' mechanical and optical properties and their dependence on production parameters were investigated, allowing for tuning of the pressure sensitivity. The fibers also withstood cyclic loading with a linear, quick response.

We produced and successfully tested a demonstrator with a matrix of intersecting fibers secured on a textile substrate.

A possible application of this textile pressure sensor would be supervision of pressure on tissue as part of pressure ulcer prevention. Pressure ulcers are prevalent in paraplegics and bedbound sick. The lack of data at skin level still makes prevention difficult. Novel flexible sensors could deliver data while preventing further injury. When combined with a photoplethysmograph, the discussed matrix is foreseen to give information on the relationship between pressure and ceasing oxygen supply in the skin.
\end{abstract}

165 words

Keywords: Melt-extrusion, polymer optical fibers, Pressure-sensing, Monitoring, Photonic sensor 


\section{Introduction}

The development of flexible sensors has always been of much interest as their application range is versatile. Their bendability or - within the area of sensing textiles - drapeability allows measurement on complex contours. However, this flexibility cannot come at the expense of sensor reliability. Flexibility can then be defined by the entire sensor set-up or by the flexibility of the substrate and the electrical connections.[1-4] When looking at the healthcare sector and medical sensors, drapeability is a determining factor for optimum fit to the body.[3] The examined vital parameters can then be recorded more reliably, with good connection to the body resulting in less motion artifacts through sensor detachment from the skin. $[1,5]$

Regarding pressure sensors, much research has been done on polymer optical fibers (POFs).[6-10] Other approaches include the use of pressure-sensing sheets.[11-13] POFs are mostly multi-mode fibers, with their advantages and disadvantages, but they are often more flexible than glass fibers.[14, 15] While they are made from various polymers, most common are PMMA fibers with specialty polymer such as CYTOP for low-loss fibers.[16] POFs are primarily produced from a preform which then also incorporates the optical cladding. An alternative method has been introduced in recent years, using the established polymer processing method melt-spinning with co-extrusion of core and cladding.[17, 18] This method is comparably fast and can be run continuously without break of the fiber. Nevertheless, requirements for optical fibers (e.g. the refractive indices) and melt-spinning (e.g. similar spinning temperatures) have to be fulfilled.

Here, we present the melt-spinning and characterization of flexible polymer optical fibers that can be used for pressure-sensing. The continuous production renders long, homogeneous fibers. These, being made from a urethane-siloxane block-copolymer, are highly elastic and pressure-sensitive. Hence, they can be used for cyclic pressure measurements. The relation between load on the fiber and light loss is investigated and the linearity of the response is used 
for sensor calibration. Additionally, a conversion to pressure is made in controlled load-driven experiments.

In the context of decubitus ulcer prevention, a possible application for these flexible sensors, the polymer optical fibres could monitor the load on tissue. Pressure sores are still highly prevalent in paraplegics and for elderly patients bound to bed. They pose a serious threat of infection with slow healing.[19-21] Such injuries then result in even lower mobility and fear of redevelopment. In an aging society, this number will rise while the causes of pressure sores are still not completely understood.[22, 23] While dropping oxygen saturation in the tissue and load on tissue is thought responsible for breakdown of microvasculature, little data is available as bulky sensors can chafe the skin or load the underlying tissue additionally.[24-26] The sensors thus increase the risk of ulcer development even further.[19, 24] Hence, recommendations are general and cannot be personalized.

With this application within the area of medical textiles and the healthcare sector, we incorporated the optical fibers into textiles to produce a demonstrator, a pressure-sensing matrix. Sensor usage could be combined with a photoplethysmograph to collect data on how pressure and oxygenation in the tissue are correlated. With these tests, a personalized prevention plan for patients suffering from decubitus ulcers could be installed.

\section{Materials and Methods}

Materials: The polymers were acquired from Wacker (Munich, Germany). The grades 100, 145, and 345 of the Geniomer line all contain more than $90 \%$ of siloxane but vary in siloxane chain length (Table 1). The glass transition temperature of the material, provided by the supplier, is $-115{ }^{\circ} \mathrm{C}$ for all the polymers. With the hard polyurethane segments, strong fibers were produced that show high elasticity during cyclic loading (due to the soft siloxane segments). The chosen Geniomer materials are used in extrusion, however, typically not for optical components. The original material was washed (with water) and dried $\left(80{ }^{\circ} \mathrm{C}\right)$ for at 
least $12 \mathrm{~h}$ in a vacuum oven before usage. This step was performed to rinse off highlydispersed silica which prevents clogging of the pellets but acts as scatterer within the optical fibers when extruded.

Table 1: Material specifications including proposed extrusion temperature from the data sheets, the softening temperatures are $170-180{ }^{\circ} \mathrm{C}$.

\begin{tabular}{|l|l|l|}
\hline $\begin{array}{l}\text { Geniomer grade } \\
{[\#]}\end{array}$ & $\begin{array}{l}\text { Siloxane chain length } \\
{[-]}\end{array}$ & $\begin{array}{l}\text { Foreseen extrusion temperature } \\
{\left[{ }^{\circ} \mathrm{C}\right]}\end{array}$ \\
\hline 100 & 15 & $165-190$ \\
\hline 145 & 40 & $170-205$ \\
\hline 345 & 150 & $160-175$ \\
\hline
\end{tabular}

Fiber spinning: Fiber melt-spinning was carried out on a customized pilot melt-spinning plant originally built by Fourné Polymertechnik (Alfter-Impekoven, Germany). Further details about the pilot melt-spinning plant can be found in the study of Hufenus et al.[27] The position of the quenching chamber, as well as cooling air temperature and flow rate were kept constant for all experiments. The dosage pressure was adjusted to 40, 70, and 100 bar for the extruder temperatures of 220,210 , and $200{ }^{\circ} \mathrm{C}$ respectively. The settings ensured a die pressure below 500 bar. For annealing purposes, a heated collar was mounted under the spinneret. The draw ratio was kept constant at 1 (no drawing) for all produced fibers. Fibers from all three grades were produced. Of these, Geniomer 100 (at a collar temperature of $150{ }^{\circ} \mathrm{C}$ ) was selected for a study on mechanical properties and their relation to production parameters of the melt-spinning process. This grade was selected due to the larger window of production temperature. The production parameters are given in Table $\mathbf{2}$ and more extensive in Table S 2. The production parameters were varied to complete a study on extruder temperature and draw-down speed. Generally, the production window was limited by exceeding maximum extruder pressure (at too low temperatures) or bubble formation in the fiber (at too high temperatures).

Between parameter setting changes of the melt-spinning process, light attenuation of the fibers was monitored with a $100 \mathrm{~mW}$ laser at $652 \mathrm{~nm}$ (Applied Optronics, South Plainfield, 
NJ, USA). The fibers were connected to a mode mixer via F-SMA connectors (Thorlabs, Newton, NJ, USA). Using an integrating sphere UM-150 (Gigahertz-Optik GmbH, Türkenfeld, Germany) and a photomultiplier tube (PRC Krochmann, Berlin, Germany), the light attenuation was measured by applying the cutback method.

The fibers' geometry, after being cut into short sections by a scalpel, was examined with a Keyence VHX-1000 Multiscan microscope (Osaka, Japan). 20 cross-sections were evaluated for determining the diameter which was subsequently used in evaluation of the mechanical properties (supposing a circular cross-section).

Table 2: Geniomer 100 fiber production parameters, the collar temperature was kept at $150{ }^{\circ} \mathrm{C}$, temperatures below 200 or above $220{ }^{\circ} \mathrm{C}$ lie outside the melt-spinning production window.* collar temperature $=180^{\circ} \mathrm{C}, * *$ collar temperature $=120{ }^{\circ} \mathrm{C}$.

\begin{tabular}{|l|l|l|}
\hline ID & Extruder temperature $\left[{ }^{\circ} \mathrm{C}\right]$ & Draw-down speed $[\mathrm{m} / \mathrm{min}]$ \\
\hline 1259 & 200 & 6 \\
\hline 1260 & 200 & 10 \\
\hline 1261 & 200 & 25 \\
\hline 1262 & 220 & 10 \\
\hline 1263 & 220 & 15 \\
\hline 1264 & 220 & 25 \\
\hline $1266^{*}$ & 220 & 15 \\
\hline 1269 & 210 & 10 \\
\hline 1270 & 210 & 15 \\
\hline 1271 & 210 & 25 \\
\hline $1273^{* *}$ & 220 & 15 \\
\hline
\end{tabular}

Mechanical testing: The fibers were tested in a fiber-specific tensile testing machine, the Statimat ME+ (Textechno, Herbert Stein GmbH \& Co. KG, Mönchengladbach, Germany) at $600 \mathrm{~mm} / \mathrm{min}$ test speed. The measurement for each fiber type was repeated 20 times. Hence, the standard deviation was calculated by error propagation taking the standard deviation of both the fiber radius and the variation along the fiber axis into account. The tensile modulus was evaluated by a secant (at $2 \%$ elongation). It was cross-compared to results achieved by simple linear regression and weighted linear least squares fit (both until $2 \%$ strain) which lay below and above respectively. Additionally, cyclic testing was performed for two cycles: one 
below plastic deformation onset (up to $10 \%$ strain) and one above (up to $200 \%$ strain). These were performed at $600 \mathrm{~mm} / \mathrm{min}$ test speed and averaged over 5 fibers.

Analysis of variance (ANOVA): For a better understanding of the effects of the production parameters on mechanical properties, we used design of experiments methodology with the runs shown in Table 2 (except for those with different collar temperature).[28, 29] We used a full factorial with two factors, draw-down speed, and extruder temperature, each at three levels, yielding 9 runs. For these experiments, the collar temperature was kept constant at $150{ }^{\circ} \mathrm{C}$. We decided to omit other collar temperatures as the short duration that the fibers experience the collar temperature setting likely does not affect the mechanical properties significantly. Two replicates of each selected fiber were performed, allowing us to determine the error with 8 degrees of freedom. For this, we designed a $3^{2}$ design of experiments (DOE), that is, two factors each at three levels. We then used ANOVA to analyze and optimize the results: Table $\mathbf{S} \mathbf{4}$ shows the parameter combinations, as well as level codification. The ninth run was not performed but estimated by the model below. With 3 levels for each factor and one missing value, we were able to fit a pure quadratic model to both responses as given in equation (1) below.[28]

$$
Y=\beta_{0}+\beta_{1} x_{1}+\beta_{2} x_{2}+\beta_{11} x_{1}^{2}+\beta_{22} x_{2}^{2}+\beta_{12} x_{1} x_{2}+\beta_{122} x_{1} x_{2}^{2}+\beta_{112} x_{1}^{2} x_{2}
$$

where $Y$ is the response (strain at break or modulus), and the $x_{i}$ represent the two studied factors: $x_{1}$ as extruder temperature, $x_{2}$ as pull-off speed, and $\beta_{\mathrm{ij}}$ the coefficient for each term of the model. Data analysis was performed with the " $R$ " program and the packages " $R$ commander" and "RemdrPlugin.DoE" (The R Foundation for Statistical Computing, Vienna, Austria).[30-32]

Attenuation measurements: The light attenuation of the optical fibers was measured from 600$1000 \mathrm{~nm}$ with a stabilized tungsten-halogen white light source (SLS201/M, Thorlabs Inc., Newton, NJ, United States). It included a $550 \mathrm{~nm}$ long-pass filter as well as an optical density filter (FGL550 and ND20B, both Thorlabs) so that full transmittance through the long-pass 
filter was reached at $600 \mathrm{~nm}$.[33] The light source connected via an SMA connector to a PMMA optical fiber (Raytela PGR-FB750 (S), Toray Industries Inc., Tokyo, Japan) secured on a xyz-stage. Correspondingly, another PMMA fiber (no cladding, $1000 \mu \mathrm{m}$ core) was secured on a second xyz-stage opposite of the first. A middle y-stage hosted the device under test (DUT), the investigated fiber on a plate covered with a Teflon-membrane for less light out-coupling. The PMMA fibers were connected to the DUT with index-matching liquid. The second PMMA fiber was then connected to a spectrometer (Andor Shamrock spectrograph 303i-A, Andor Technology Ltd., Belfast, UK) equipped with a high-speed CCD camera (iDus DV 420A-OE, Andor). An in-house written Labview code allowed for alignment of the axes of the connecting PMMA to the DUT.[34] By adjusting the stages, the maximally transmitted intensity is reached. Spectrometer data for that setting was then recorded at the highest possible integration time without saturation $(\leq 60000$ counts $)$ for optimum signal-to-noise ratio. The measurement was repeated for three different fiber samples (of ID-1266) to calculate an average attenuation.

Sensor calibration: For usage of the fibers as pressure sensors, the fibers' response was used for calibration. Hence, the response to load, initially of a single fiber, was logged. With this, the deformation of solely the pressure-sensitive fiber was analyzed. All samples were spliced to PMMA fibers, as in the attenuation set-up. However, to secure the connection during measurement, instant glue was used. The set-up was equipped with an LED E-91a (peak wavelength $=940 \mathrm{~nm}$ ) and phototransistor PT D-92 (maximum photosensitivity at $870 \mathrm{~nm}$ ). Both were acquired from industrial fiber optics (Tempe, AZ, USA). The fibers were then tested with a universal test machine of type Zwick 1484 (Ulm, Germany). The load was applied using a custom-made cylindrical stamp of radius $5 \mathrm{~mm}$, aligned transversely to the tested fiber. A flat base plate was used as lower support. The stamp as well as the base plate were silver-coated (thickness: $40 \mathrm{~nm}$ ) by plasma deposition. With this, the surfaces obtained a lower refractive index than that of the optical fiber core and acted as a cladding during the 
tests, just like air otherwise thus avoiding light out-coupling due to mere contact. The set-up was additionally shielded from environmental light by a curtain. The electrical circuit was connected to the Zwick test machine as an external sensor via a low-noise amplifier.

The conversion from load to pressure was calculated from the displacement of the stamp (in vertical direction, into the soft fiber). The area of contact between the stamp and the fiber was defined as that of two perpendicular cylinders (with one being much stiffer than the other). Indentation distance hence defined deformation of the fiber. Experienced load or pressure was then linked to the voltage detected in the LED-PT system by the time stamp.

Sensor prototype testing: For measuring the pressure distributed over the seating area (e.g. in a wheelchair), a pressure matrix was designed which utilizes 6 channels each for light sources and detectors. With this, a 3X3 matrix with 9 measurement points could be produced (Figure 1 (left)). Detector values could then be linked to the spatial pressure mapping by linear combination. The prototype in this study consisted of two polymer fibers forming a $1 \mathrm{X} 1$ matrix so that it could be used under compression in the universal testing machine. The fibers were introduced into a thin, black, breathable polyester membrane (Sympatex, Unterföhring, Germany), laser welded to form the optical fiber-crossing. The used electronics converted the normalized voltage into load readings using a two-point calibration. The data was then sent to a computer via Bluetooth to visualize the response on screen in real time.
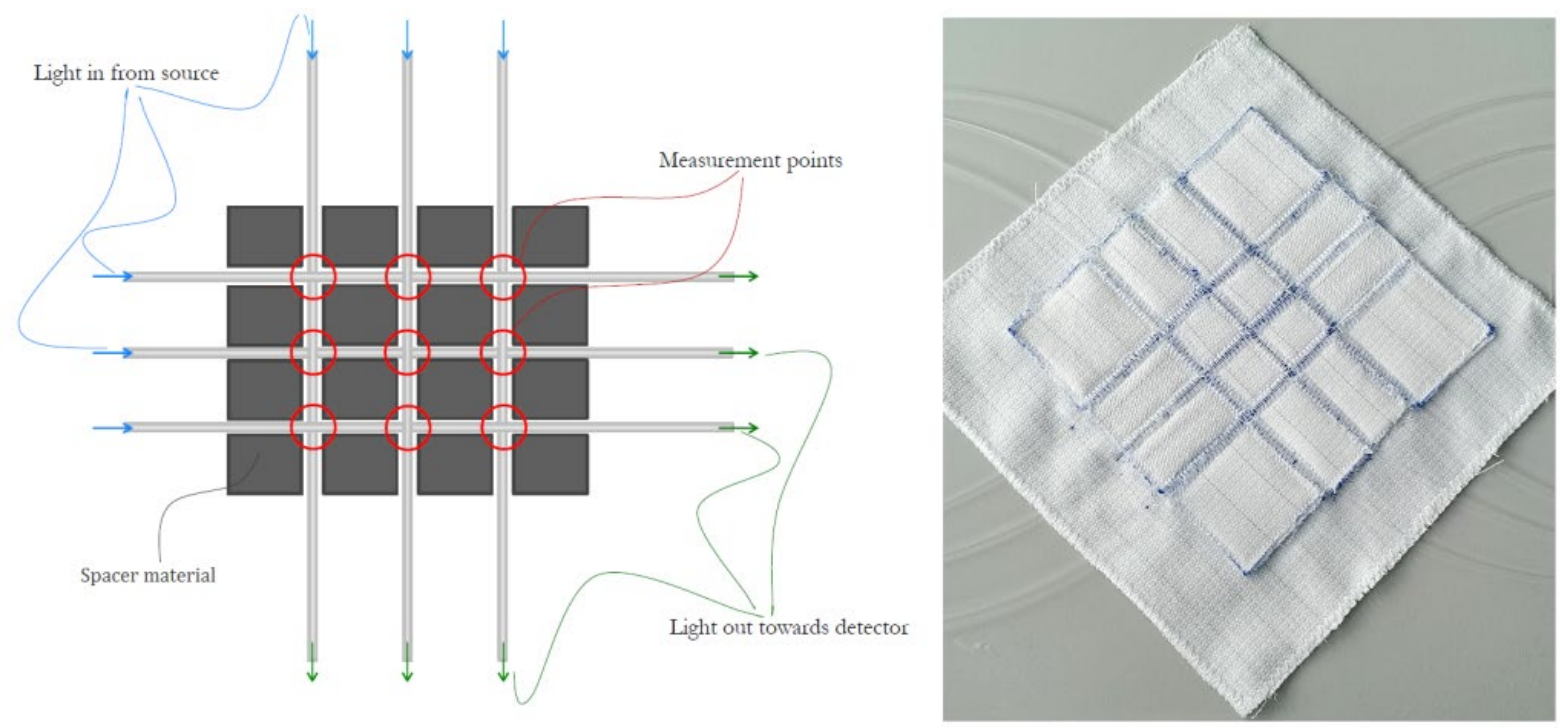
Figure 1: Pressure-sensing matrix for measurement of distribution of load: (left) schematic, (right) prototype made with a decubitus bedsheet (Schoeller Textil) for low friction as substrate. The pressure-sensitive fiber is spliced to PMMA fibers as described.

\section{Results and Discussion}

Mechanical testing: All produced fibers from the Geniomer 100, 145, and 345 grades have been tested for tensile properties with the ranges of strain at break and tensile modulus given in Table 3 (upper section) with the properties for each fiber ID given in Table S 3.

The strongest difference from the data sheets and our measured fibers is the ordering of the three grades for the elongation at break (also Table 3, lower section). It has to be noted, however, that the properties do not necessarily have to fit the data sheet, as the tested specimens for the data sheet were not melt-spun and vastly different extrusion temperatures were used for Geniomer 100 and 345 (compare to Table 1, foreseen extrusion temperature). For the different Geniomer grades, the tensile modulus each time increases by a factor of approximately 10 from the one with the longest siloxane chain (345) to grade 145 to the one with the shortest siloxane chain (145), see Table 3 and Table S 3. Even though the fibers were not produced at the same extrusion temperature, we compared the mechanical tests as the materials' individual window of production limited them to these temperatures.

A typical stress-strain-curve is given with Figure 2 (a). Each shaded area shows the standard deviation from one fiber resulting from the calculation into stress with taking the fiber diameter standard deviation into account, resulting in two lines (upper and lower end of range) for each repetition. Most notably missing from the curves are necking effect or strain hardening within the plastic deformation range. Figure 2 (b) and (c), however, show the behaviour of the fibers under cyclic, tensile loading. The fibers recover well up to $10 \%$ strain, within the elastic deformation range, derived from the standard testing's initial slope. Higher strains as seen in Figure 2 (c) lead to only partial recovery. This can be observed by the shifted start of each additional cycle. Additionally, a change in curve shape with more and 
more pronounced strain hardening effect starting from the second cycle is obtained. Cycles 2 to 5 (to $80,120,160$, and $200 \%$ strain) hence show the previous drawing cycles. The drawing history of the fiber can be observed.
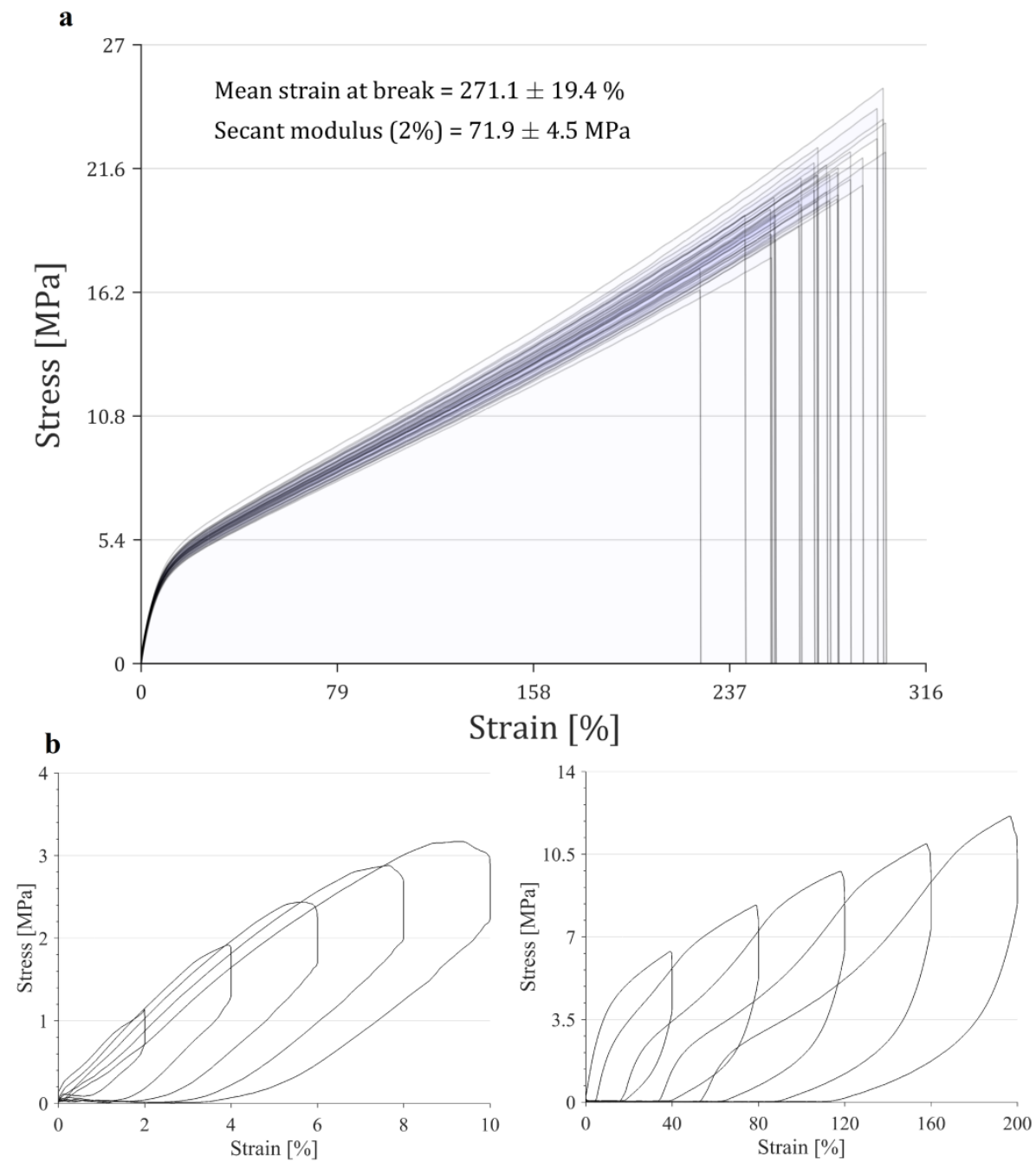

Figure 2: (a) Standard mechanical testing of fiber ID-1266, the fiber used in the pressure cycles and calibration; (b) and (c) show the hysteresis behaviour of the same fibers up to 10 and $200 \%$ strain respectively, also tested at $600 \mathrm{~mm} / \mathrm{min}$ with the mean value of 5 measurements shown. 
Table 3: Range of mechanical properties of the three Geniomer types for our fibers; the tensile modulus is evaluated by a secant at $2 \%$ strain; in the lower section the mechanical properties are given as noted in the data sheets.

\begin{tabular}{|l|l|l|l|}
\hline & Grade & Strain at break [\%] & Tensile Modulus [MPa] \\
\hline \multirow{3}{*}{ Present study } & 100 & $102 \ldots 282$ & $49.9 \ldots 89.5$ \\
\cline { 2 - 4 } & 145 & $548 \ldots 576$ & $6.6 \ldots 8.5$ \\
\cline { 2 - 4 } & 345 & $95 \ldots 205$ & $0.5 \ldots 0.7$ \\
\hline \hline \multirow{3}{*}{ Material datasheet } & Grade & Elongation at break [\%] & Tensile Strength [MPa] \\
\cline { 2 - 4 } & 100 & $>500$ & $>4$ \\
\cline { 2 - 4 } & 145 & $>400$ & $4-8$ \\
\cline { 2 - 4 } & 345 & $>300$ & 1 \\
\hline
\end{tabular}

The mechanical tests showed that the different grades of polymer had a strong influence on both strain at break as well as tensile modulus (Table S 3). Considering only the fibers produced from Geniomer 100, the strain at break correlates to both extruder temperature and draw-down speed as can be seen in Figure 3. We hypothesized a correlation between the strain at break of the fiber and its sensitivity to pressure. Therefore, in order to better understand the effect of processing parameters during melt-spinning on the mechanical properties we selected grade 100 for a detailed statistical study (Table 4). The polymer optical fibers made from Geniomer 145 and 345 were only produced at one extruder temperature as the window of production was much smaller and these were hence not included in the statistical investigation.

Table 4: List the mechanical properties of the Geniomer 100 fibers; the strain at break as well as the secant modulus is given with the standard deviation from 20 measurements; all have been examined by ANOVA.

\begin{tabular}{|l|l|l|}
\hline ID & Strain at break [\%] & Tensile modulus [MPa] \\
\hline 1259 & $214.5 \pm 18.0$ & $84.96 \pm 7.75$ \\
\hline 1260 & $172.2 \pm 12.8$ & $79.48 \pm 4.55$ \\
\hline 1261 & $101.9 \pm 29.7$ & $89.47 \pm 8.60$ \\
\hline 1262 & $282.0 \pm 44.6$ & $56.73 \pm 3.69$ \\
\hline 1263 & $267.9 \pm 20.7$ & $57.46 \pm 4.28$ \\
\hline 1264 & $198.6 \pm 40.1$ & $64.29 \pm 4.86$ \\
\hline 1269 & $234.7 \pm 15.0$ & $71.46 \pm 3.50$ \\
\hline 1270 & $201.2 \pm 12.3$ & $83.47 \pm 5.41$ \\
\hline 1271 & $159.7 \pm 13.1$ & $76.71 \pm 4.81$ \\
\hline
\end{tabular}




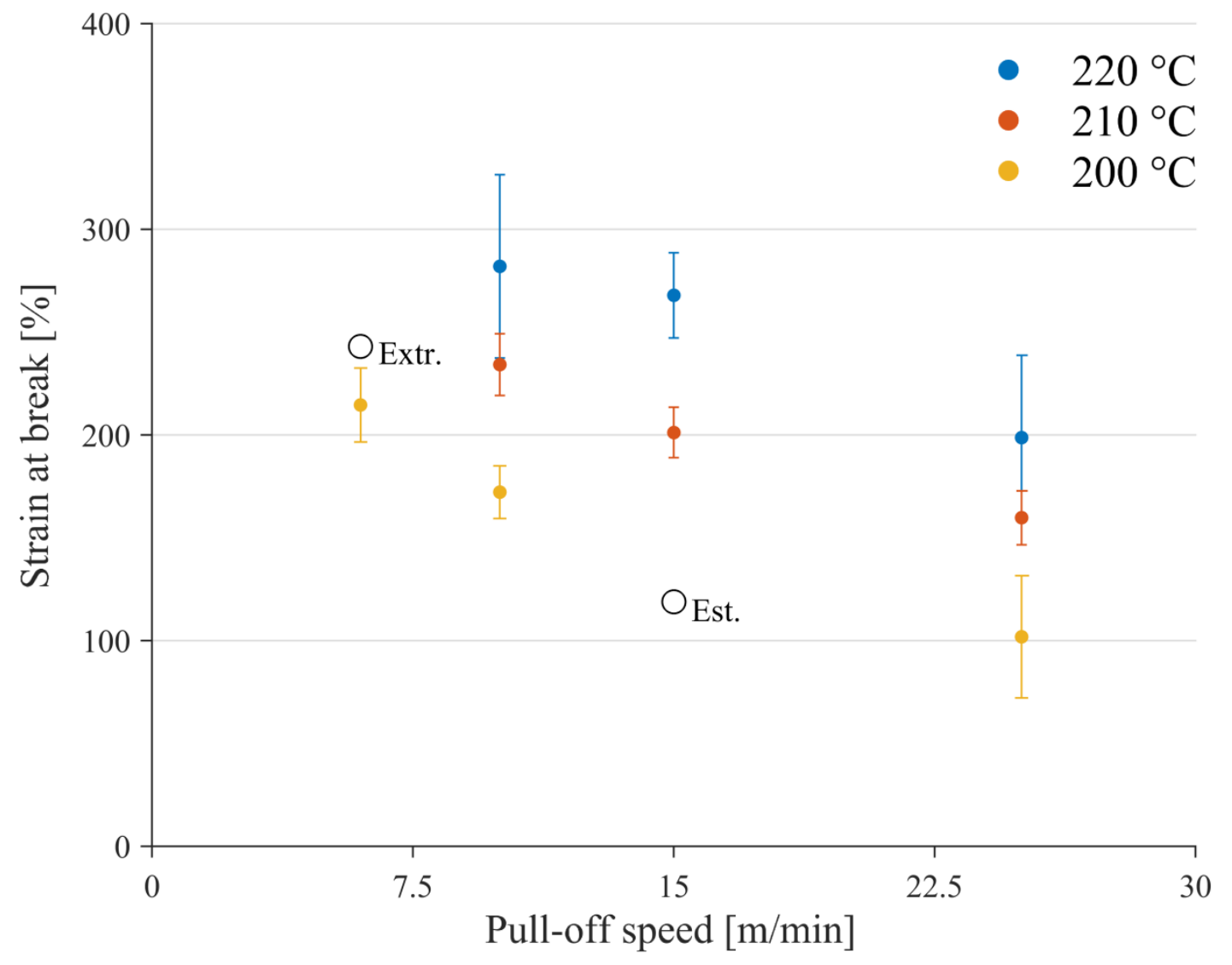

Figure 3: Strain at break of Geniomer 100 fibers against the draw-down speed at different extruder temperatures; for $200{ }^{\circ} \mathrm{C}$ extruder temperature, an estimation of the strain at break at $15 \mathrm{~m} / \mathrm{min}$ pull-off speed has been calculated by ANOVA. Similarly, an extrapolation from the ANOVA equation is plotted for $6 \mathrm{~m} / \mathrm{min}$.

Analysis of variance (ANOVA):

We performed the runs as shown in Table $\mathbf{S}$ 4. The data both strain and modulus were fitted according to equation (1). The calculated coefficients $\beta$ for each term of the model are given in Table S 5 and Table S 6 (together with their respective errors) for each response. Table 5 shows the ANOVA results for both models. The individual effects (speed or temperature) are highly significant for both properties, and that basically no interaction between these two factors are present. A marginal significance of TWI for the modulus was observed, however, given that one value is missing, this significance should be taken with care. The coefficients shown in Table S 5 and Table $\mathbf{S} \mathbf{6}$ clearly show the behaviour of both factors being opposite: 
increasing the extruder temperature leads to lower moduli and higher strains at break, a similar effect being obtained when decreasing the pull-off speed.

The strain at break may be described by a simple linear model, since only the linear components of the factors are significant to determine the variability in the model. This linear relationship between strain at break and both variables is also shown in Figure 3. For the secant modulus, on the other hand, we did observe curvature effects associated with the pulloff speed, leading also to a significant interaction effect (term $\left.x_{1} x_{2}^{2}\right)$.

We then used the models to calculate the missing values, obtaining a value of $105 \mathrm{MPa}$ and $118 \%$ for the modulus and strain at break, respectively. These values are shown both in Figure 3 and in Table 5. Moreover, we also used the model to extrapolate the predictions beyond, but close to, the model boundary. As shown in Figure 3, the estimated extrapolated value for $200{ }^{\circ} \mathrm{C}, 6 \mathrm{~m} / \mathrm{min}$ agrees well with the measured data. In summary, with the ANOVA model, we could successfully estimate the strain at break for any combination of production parameters in the studied range. Following our hypothesis of a correlation between strain at break and pressure sensitivity, we could then select the production parameters that would yield fibers with the adequate sensitivity range for any desired application.

Table 5: ANOVA for the mechanical properties, showing the factors with significant effects in boldface. ${ }^{\text {a) }} \mathrm{df}=$ degrees of freedom; ${ }^{\text {b) }} \mathrm{SS}=$ sum of squares; ${ }^{\mathrm{c})} \mathrm{MS}=$ mean square, ${ }^{\mathrm{d}} \mathrm{TWI}=$ twoway interaction.

\begin{tabular}{|c|c|c|c|c|c|c|}
\hline & & $\left.d^{a}\right)^{a}$ & $\mathbf{S S}^{\mathbf{b})}$ & $\mathbf{M S}^{\mathrm{c})}$ & F value & $\operatorname{Pr}(>\mathbf{F})$ \\
\hline \multirow[t]{4}{*}{ Strain at break } & Extruder T & 2 & 30508 & 15254 & 139.713 & $6.00 \mathrm{e}-07$ \\
\hline & Pull-off speed & 2 & 18025 & 9013 & 82.548 & $4.56 \mathrm{e}-06$ \\
\hline & $\mathrm{TWI}^{\mathrm{d})}$ & 3 & 450 & 150 & 1.375 & 0.319 \\
\hline & Residuals & 8 & 873 & 109 & & \\
\hline \multirow[t]{4}{*}{ Secant modulus } & Extruder T & 2 & 1720.0 & 860.0 & 98.885 & $2.28 \mathrm{e}-06$ \\
\hline & Pull-off speed & 2 & 200.7 & 100.3 & 11.538 & 0.00439 \\
\hline & TWI ${ }^{d)}$ & 3 & 114.2 & 38.1 & 4.377 & 0.04217 \\
\hline & Residuals & 8 & 69.6 & 8.7 & & \\
\hline
\end{tabular}

Optical Properties: The attenuation spectrum was recorded three times for averaging the intensity value at each investigated fiber length. This method accounts for the difficulty of 
obtaining a smooth, perpendicular fiber cut. As the soft, rubbery fibers cannot be polished, the light intensity can be artificially low due to light scattering effects at the interface. Figure 4 shows the attenuation loss over the spectrum of $600-1000 \mathrm{~nm}$. The inset shows how each data point in the main graph is obtained: The slope of the linear fit gives the light loss at the respective wavelength. The noise above $870 \mathrm{~nm}$ is due to the initial signal being low, just above the background value. It was not possible to increase the integration time, however, without saturating between 700 and $800 \mathrm{~nm}$ (>60000 counts). The near-infrared region hence shows here a low signal-to-noise ratio. The minor peaks in the attenuation spectrum can arise from atom bond stretching or oscillations.

Finally, though the attenuation of the fibers cannot compare to communication fibers, it is adequate for the short fiber lengths that are required in the sensor.

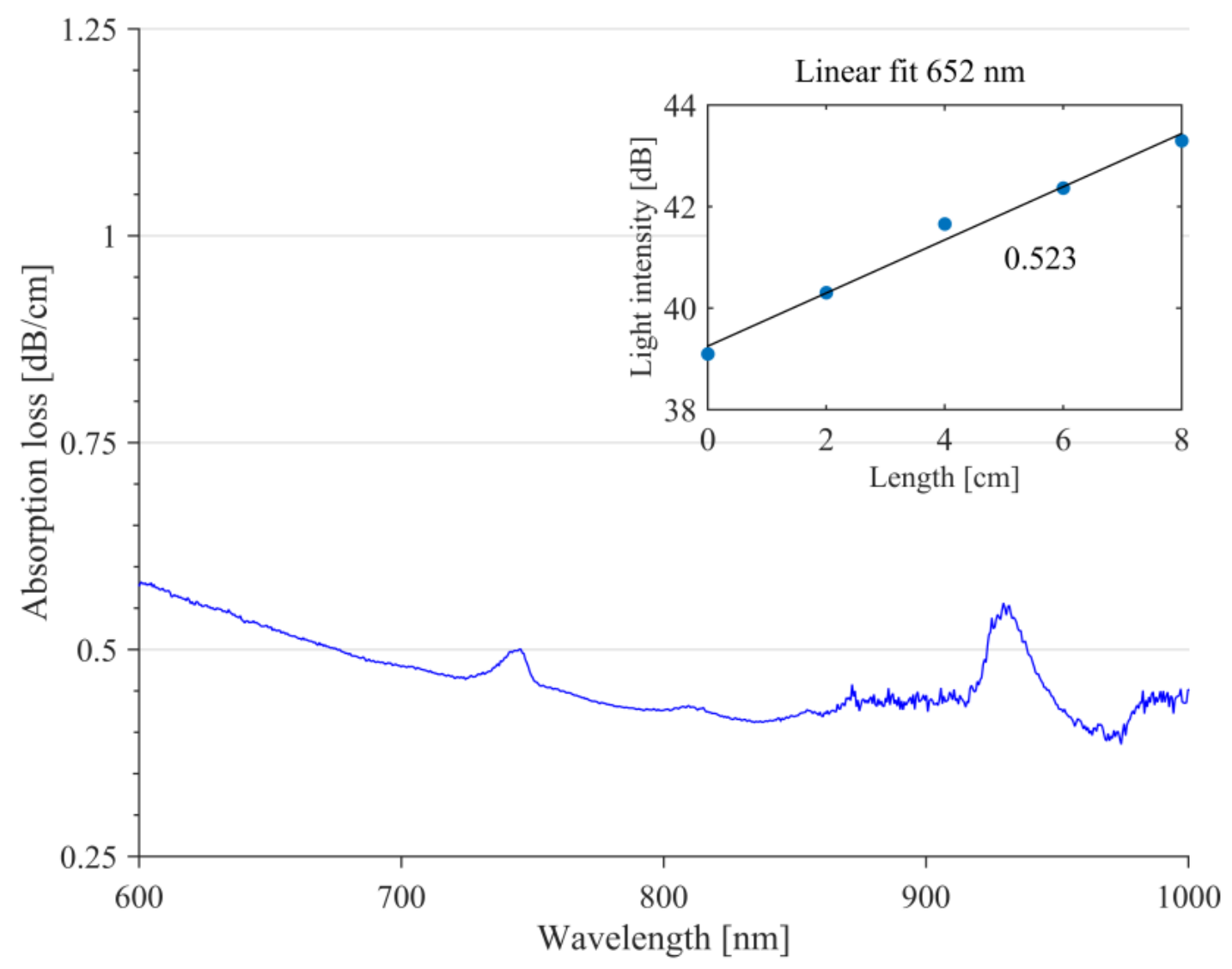

Figure 4: Attenuation spectrum of fiber ID-1266 over the range from 600 to $1000 \mathrm{~nm}$. The value at each measurement point is calculated from the average of three measurements. The noise for 
$\lambda>870 \mathrm{~nm}$ results from a lower signal-to-noise ratio (see text); the inset shows the attenuation at $652 \mathrm{~nm}$, given by the slope of the linear fit of light intensity plotted against fiber length.

Sensor response to load: The pressure-sensitive fibers spliced to connector PMMA fibers have been evaluated and consequently calibrated to the load and converted pressure they have been subjected to. We chose an LED with a peak wavelength within the near-infrared region both because it is the lowest attenuation region of our fibers as well as being suitable for the selected photodiodes and -transistors. With the phototransistor being less sensitive to visible light, remaining environmental light (inside the darkened chamber) and changes thereof can be neglected. Figure 5 (left) shows the response of the fiber ID-1266 to load ranging from 1 to $6 \mathrm{~N}$ in $0.5 \mathrm{~N}$ increments. All experiments included holding the load for 5 seconds, visible by the decrease in normalized voltage. After release, the voltage quickly returned to $100 \%$ for all loads.
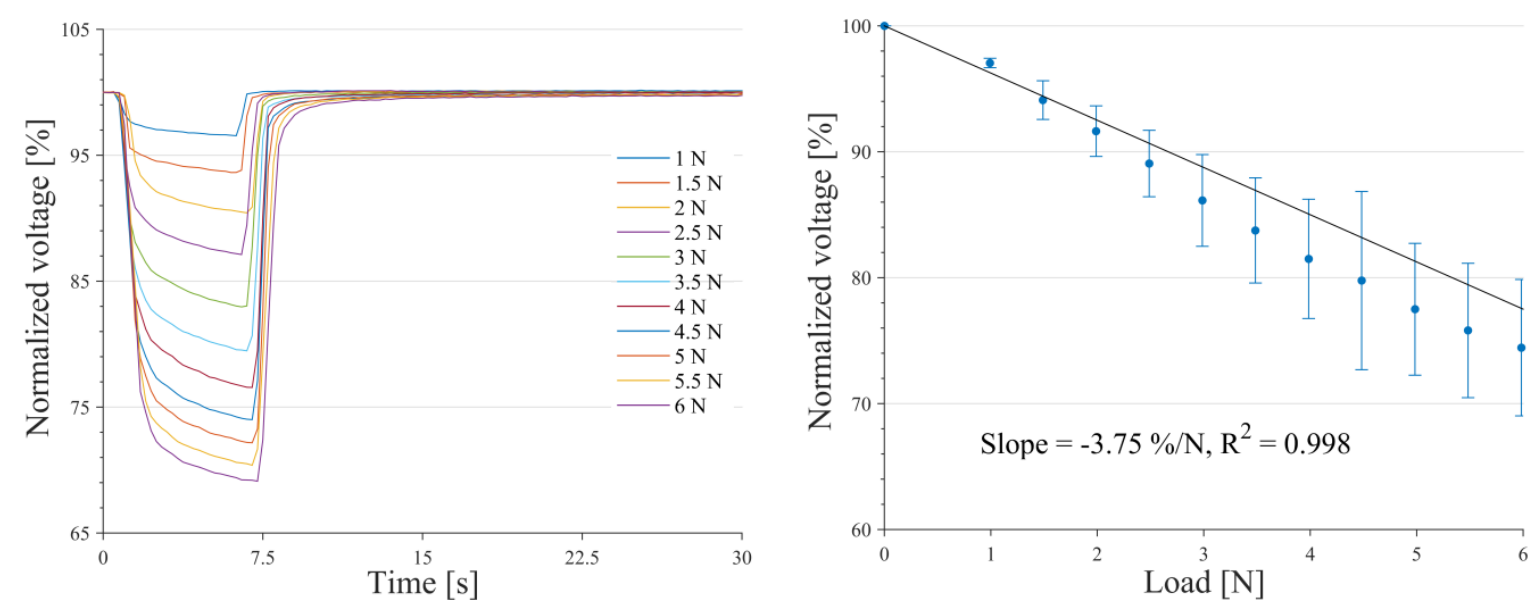

Figure 5: (left) Response of fiber ID-1266 from 1 up to $6 \mathrm{~N}$ and the relaxation after loadremoval; (right) Calibration data of a Geniomer 100 (ID-1266) pressure-sensitive fiber. The error bars stem from 3 repetitions on different fiber samples. The fit stems from a weighted linear least squares fit which takes the standard deviation of each measurement point into account (weighted maximum likelihood method).

Taking the average response of three measurements as described above (at the peak of the applied load), a calibration for fiber ID-1266 could be done (Figure 5 (right)). The slope gives the light loss per applied load. With a weighted maximum likelihood method, an $\mathrm{R}^{2}$ - 
value of 0.998 was obtained. The standard deviation for the load was taken as $1 \%$ at each data point for the calculation.

Reversibility of sensor switch: In Figure 5, we showed that the initial state was recovered after approximately 3 seconds. The fiber responded quickly to changes in pressure. We tested the set-up in long-term measurements of 250 cycles $(\sim 5 \mathrm{~h})$ to verify that the fiber could be used in a clinical setting where it has to withstand many loading/unloading-cycles. The fibers have proven to return to the initial intensity after completion of a test cycle after compensation (by linear fit) for upwards drift of the electronics. The response can also be compared well to the fit in Figure 5 for $1 \mathrm{~N}$ load $(3.75 \%$ decrease of measured voltage for 1 $\mathrm{N}$ load). The 250 cycles can be seen in Figure 6 with an inset of 4 cycles after 6000 seconds of testing. The initially obtained voltage data is converted to signal change as to simplify comparison with other fibers. The mean response was added to the plot as a dotted line for better visual aid. The stability of the response is well demonstrated after compensation for drift of the electronics. The mean remaining drift amounts to $0.002 \% /$ cycle. 


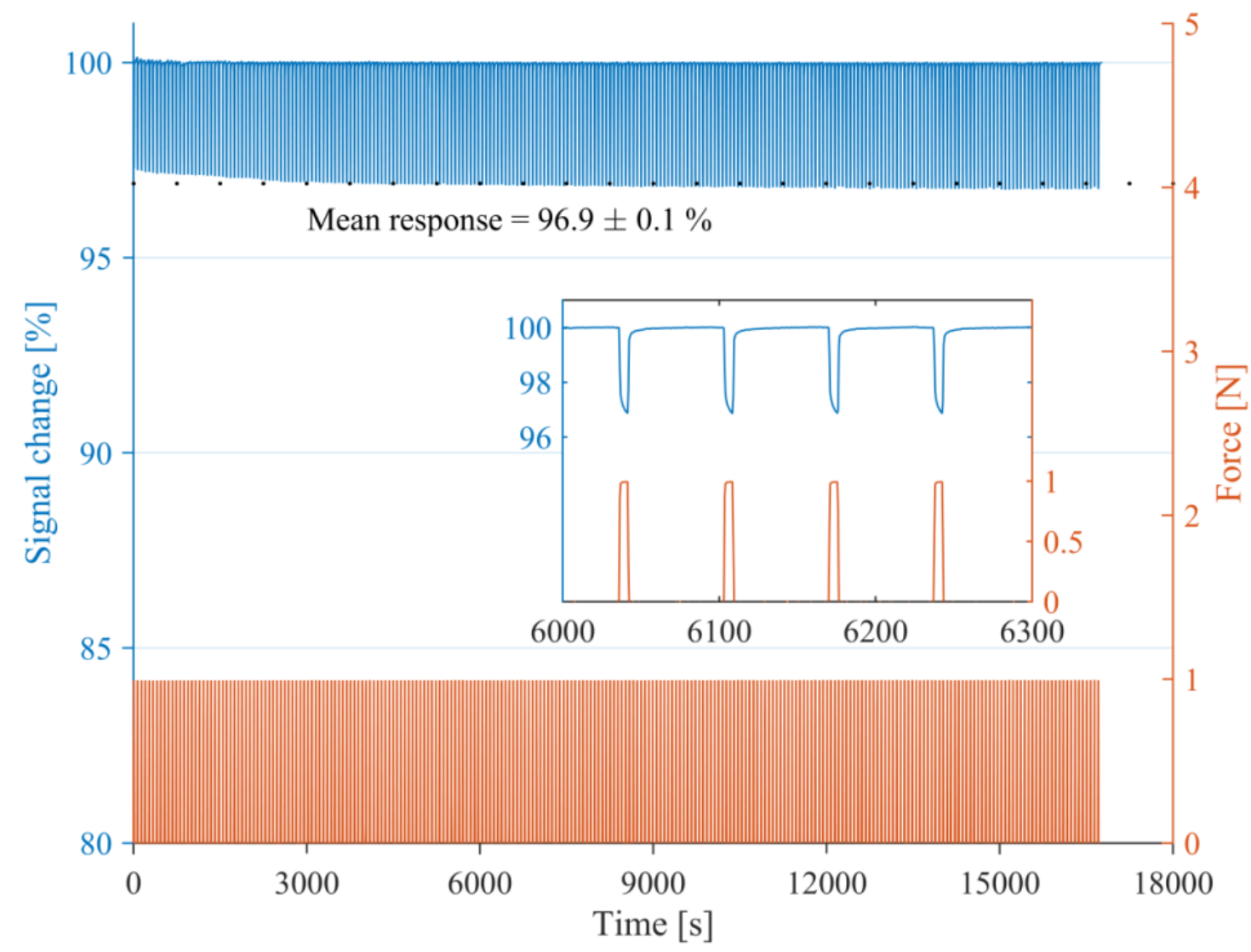

Figure 6: 250 load cycles on a Geniomer 100 fiber (1266) with the load data (red) and the response (blue); the minimum of each cycle is averaged and given as mean response including the dotted line; the inset image shows a magnification of 4 cycles. The signal change is calculated from the most previous peak, hence compensating for electronics drift.

Finally, the load values have been converted to pressure and the relation between loss of light and pressure was logged (Figure 7). The pressure conversion is highly dependent on the stiffness of the material as the travelled path into the fiber (= the displacement of the stamp) is included in the conversion. Just as for load, the light loss increases with increasing pressure. For this conversion, the fiber material grade and production parameters generally play a much bigger role: For a very soft fiber (e.g. those of Geniomer 345), a specified load is only reached at much higher indentation depth and hence much higher light loss. Within one material grade, the fiber diameter plays a role in contact area calculation. For the fibers we tested, a trend of a stronger response at higher siloxane chain length (that is, lower tensile modulus) could be observed. This confirms the importance of tailoring the mechanical properties by 
using the ANOVA model: by selecting the adequate processing parameters, we are able to produce fibers with well-defined pressure sensitivity.

This is additionally demonstrated in Figure $\mathbf{S} 2$ showing fiber ID-1263. The experiment was performed the same as with fiber ID-1266 in Figure 7, but shows a different contact area (and hence pressure value) as well as light response. The two fibers only differ in collar temperature.

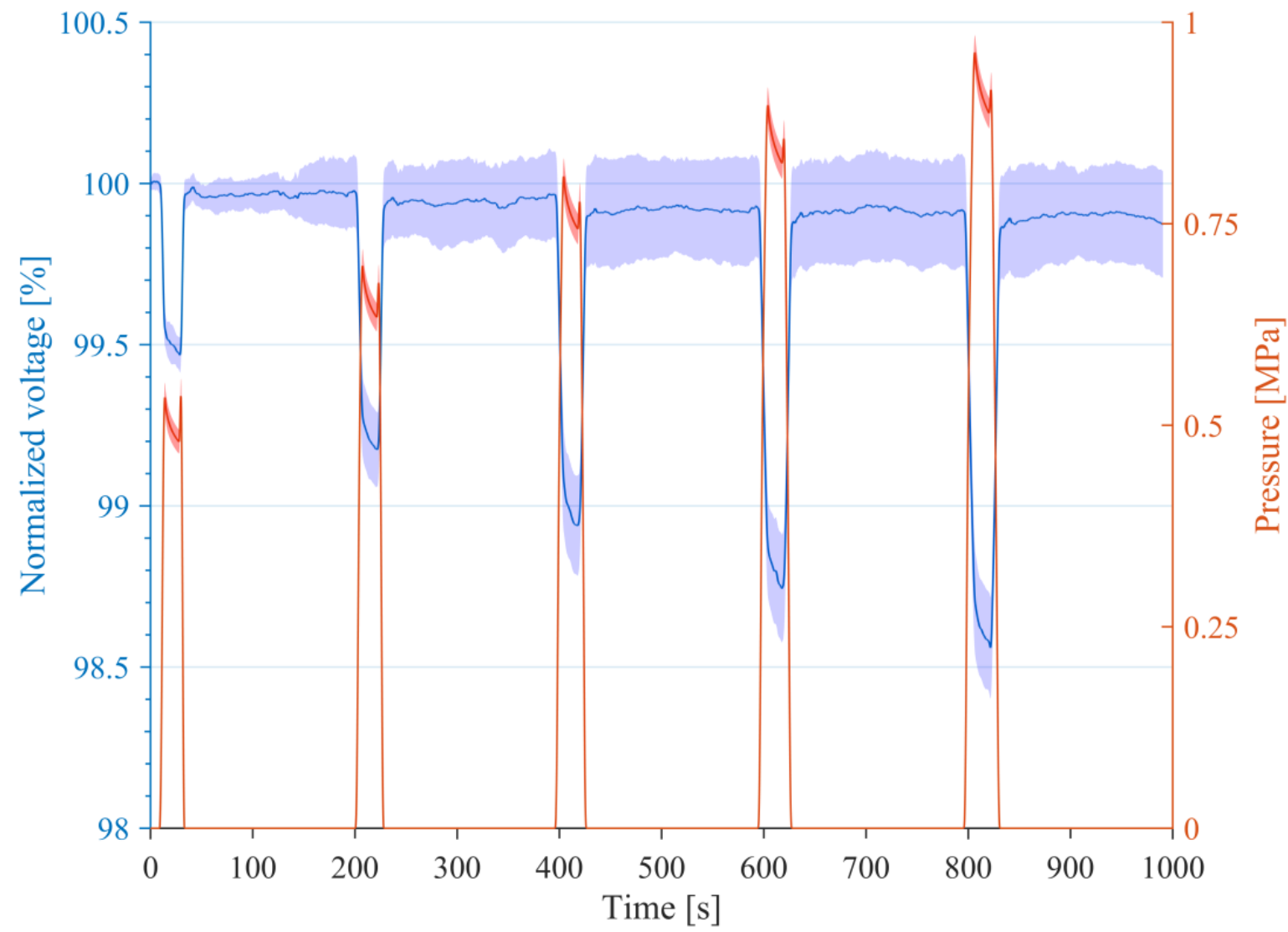

Figure 7: Conversion of load cycles to pressure with the corresponding response of the fiber (ID1266); the length of the fiber is $15 \mathrm{~cm}$; mean as well as upper and lower standard deviations are plotted for both applied pressure and normalized voltage. The fiber was increasingly loaded with $3,6,9,12$, and $15 \mathrm{~N}$.

Pressure sensor in practical application: A 1X1 matrix (simplified from Figure 1) was tested under the tensile testing machine. The slope of linear fit previously introduced (Figure 5 (right)) was used to convert the light loss to load in real time. As both fibers in the crossing 
are deformed under load, both channels have to be logged. The total response is received by summing the response of fibers 1 and 2 .

Figure 8 shows both the sample in the compression tester (left) as well as the response from the sensor (right). The initial response is slightly lower than the expected $1 \mathrm{~N}$, which is due to some of the load distributed on the substrate fabric since the calibration was done on sole fibres. The data is not compensated for drift but shown as received. The drift is thought to arise from the heating up of the electronics.
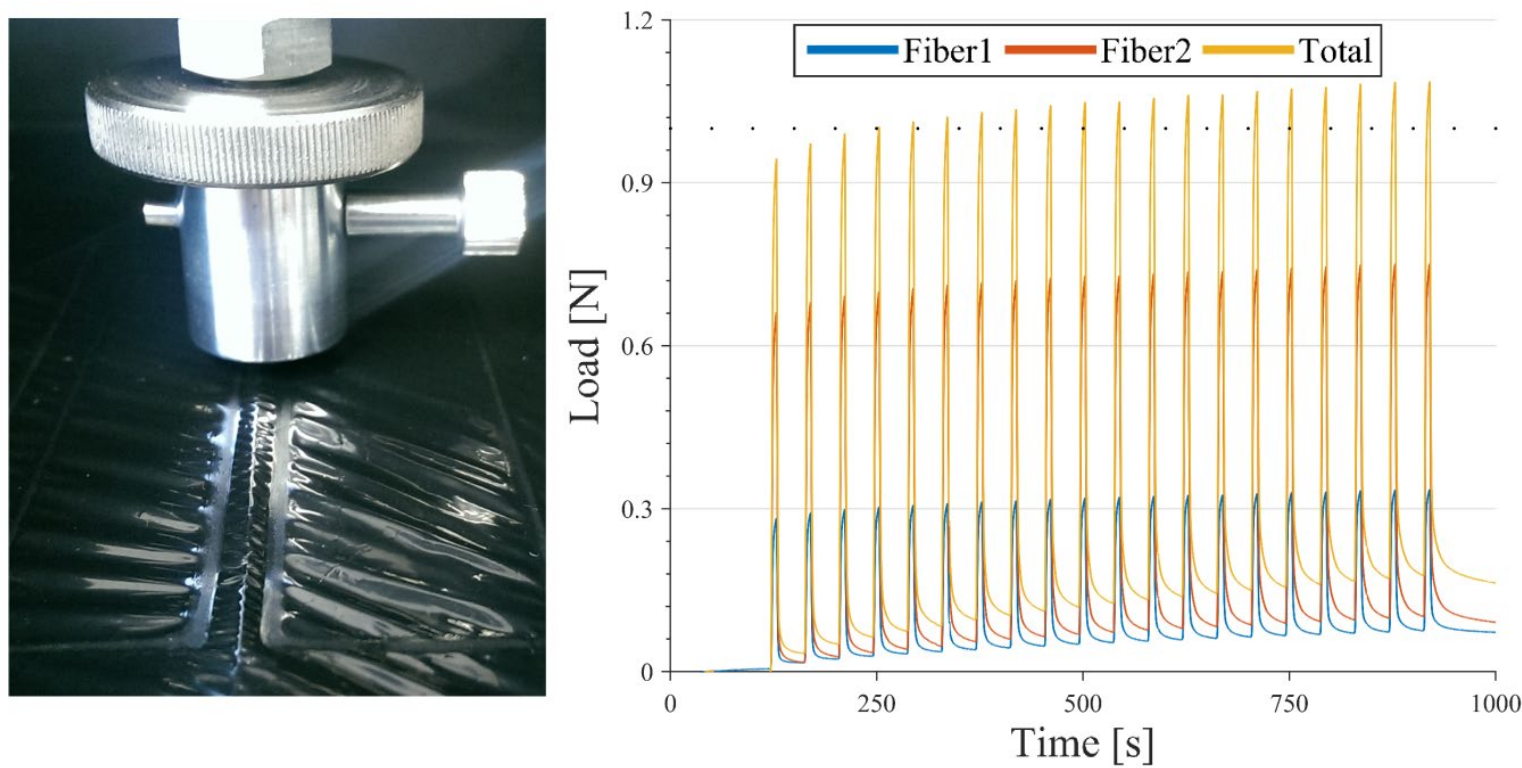

Figure 8: (left) Stamp above the Sympatex membrane; the optical fiber is inserted and can be seen between the welded lines in the membrane; (right) Load experienced by the sensing matrix of fiber 1253 when loaded 20 times with $1 \mathrm{~N}$, experienced load of each channel is added up to receive the total load; a dashed line is added at $1 \mathrm{~N}$ which was the load actually applied by the compression tester.

\section{Conclusion and Outlook}

In this paper we demonstrate the continuous melt-spinning of pressure-sensitive polymer optical fibers. The extrusion process offers a one-step approach for producing functional POFs. Our fibers respond to pressure without the need of any further post-processing treatment. The mechanical properties, an important predictor for the sensitivity of the POFs to pressure, have been shown to be linked to drawing speed and extruder temperature. We could 
therefore easily tailor the POFs to different application needs, by changing of the polymer grade or the processing parameters. The optical properties are moreover appropriate for a short-range sensing application.

The fiber production process is easy, fast, large-scale and cheap. The fibers additionally allow for incorporation into textiles for wearable sensor applications. Such sensors could find wide use in the long-term monitoring of sensitive patients, due to their versatility, flexibility, and reliability. Being fully textile-based, they could be easily incorporated into everyday-use products and therefore provide an inconspicuous product for the patient. This product then allows to understand skin physiology with focus on pressure ulcer development and to provide options for individualized monitoring.

\section{Acknowledgements}

This project is funded by Nano-Tera.ch (within the ParaTex and ParaTex-Gateway project) with Swiss Confederation financing. Thanks to Benno Wüst for his help in extruding the fibers as well as Hans Michel for the cyclic testing. Dirk Hegemann shall be thanked for the silver plasma coating of the stamps and base plate for mechanical testing. Marisa Pfister has contributed to the data acquisition on mechanical properties.

\section{Supporting Information}

The mechanical tests were performed to reach break within 30 seconds for the most-used Geniomer 100 fibers. It was hence fixed at $600 \mathrm{~mm} / \mathrm{min}$. For comparison, the tensile strength and strain at break was also evaluated for different speeds with the results in Table $\mathbf{S} \mathbf{1 .}$ 
Table S 1: Properties of 1266 at different testing speeds, with the average duration of the tensile tests given as well.

\begin{tabular}{|l|l|l|l|}
\hline Drawing speed & Average duration $[\mathrm{s}]$ & Strain at break [\%] & Secant modulus [Pa] \\
\hline 5 & $3584 \pm 410$ & $297.4 \pm 35.4$ & $37.70 \pm 1.45$ \\
\hline 10 & $1645 \pm 560$ & $272.8 \pm 99.4$ & $39.87 \pm 2.76$ \\
\hline 100 & $173 \pm 29$ & $287.2 \pm 47.4$ & $49.12 \pm 3.13$ \\
\hline 300 & $50 \pm 20$ & $248.9 \pm 99.5$ & $52.90 \pm 1.19$ \\
\hline $\mathbf{6 0 0}$ & $\mathbf{3 2} \pm \mathbf{5}$ & $\mathbf{3 1 5 . 8} \pm \mathbf{5 1 . 3}$ & $\mathbf{5 5 . 9 6} \pm \mathbf{2 . 7 3}$ \\
\hline 1200 & $14 \pm 2$ & $280.1 \pm 36.9$ & $58.99 \pm 1.22$ \\
\hline 2400 & $7.7 \pm 0.5$ & $308.3 \pm 19.1$ & $53.38 \pm 4.09$ \\
\hline
\end{tabular}

The corresponding mechanical properties including those of grade 100 are given in Table S 3, with the mechanical properties of the grades 145 and 345 noted as well. Table $\mathbf{S} 2$ shows the production parameters of the fibers from grade 145 and 345.

Table S 2: Production parameters of the Geniomer fibers produced from grades 145 and 345.

\begin{tabular}{|l|l|l|l|}
\hline$\#$ & Extruder temperature $\left[{ }^{\circ} \mathrm{C}\right]$ & Collar temperature $\left[{ }^{\circ} \mathrm{C}\right]$ & Pull-off speed $[\mathrm{m} / \mathrm{min}]$ \\
\hline 1251 & 195 & 150 & 15 \\
\hline 1252 & 195 & 150 & 12 \\
\hline 1253 & 195 & 150 & 18 \\
\hline 1254 & 195 & 150 & 21 \\
\hline 1276 & 210 & 180 & 10 \\
\hline 1277 & 210 & 180 & 8 \\
\hline 1278 & 210 & 180 & 15 \\
\hline 1279 & 210 & 150 & 10 \\
\hline 1280 & 210 & 150 & 15 \\
\hline 1281 & 210 & 150 & 18 \\
\hline
\end{tabular}


Table S 3: Mechanical properties of all of the produced optical fibers; the tensile modulus is evaluated at $2 \%$ strain.

\begin{tabular}{|l|l|l|l|}
\hline Geniomer type & ID & Strain at break [\%] & Tensile Modulus [MPa] \\
\hline 145 & 1251 & $563.1 \pm 38.8$ & $6.64 \pm 0.61$ \\
\cline { 2 - 4 } & 1252 & $551.8 \pm 51.9$ & $7.56 \pm 1.19$ \\
\cline { 2 - 4 } & 1253 & $576.4 \pm 33.2$ & $8.49 \pm 2.03$ \\
\cline { 2 - 4 } & 1254 & $547.6 \pm 74.6$ & $8.02 \pm 1.26$ \\
\hline 100 & 1259 & $214.5 \pm 18.0$ & $84.96 \pm 7.75$ \\
\cline { 2 - 4 } & 1260 & $172.2 \pm 12.8$ & $79.48 \pm 4.55$ \\
\cline { 2 - 4 } & 1261 & $101.9 \pm 29.7$ & $89.47 \pm 8.60$ \\
\cline { 2 - 4 } & 1262 & $282.0 \pm 44.6$ & $56.73 \pm 3.69$ \\
\cline { 2 - 4 } & 1263 & $267.9 \pm 20.7$ & $57.46 \pm 4.28$ \\
\cline { 2 - 4 } & 1264 & $198.6 \pm 40.1$ & $64.29 \pm 4.86$ \\
\cline { 2 - 4 } & 1266 & $271.1 \pm 19.4$ & $71.86 \pm 4.53$ \\
\cline { 2 - 4 } & 1269 & $234.7 \pm 15.0$ & $71.46 \pm 3.50$ \\
\cline { 2 - 4 } & 1270 & $201.2 \pm 12.3$ & $83.47 \pm 5.41$ \\
\cline { 2 - 4 } & 1271 & $159.7 \pm 13.1$ & $76.71 \pm 4.81$ \\
\cline { 2 - 4 } & 1273 & $231.1 \pm 19.9$ & $57.85 \pm 2.88$ \\
\hline 345 & 1276 & $172.1 \pm 49.1$ & $0.62 \pm 0.03$ \\
\cline { 2 - 4 } & 1277 & $181.1 \pm 46.5$ & $0.49 \pm 0.02$ \\
\cline { 2 - 4 } & 1278 & $153.3 \pm 55.8$ & $0.70 \pm 0.02$ \\
\cline { 2 - 4 } & 1279 & $204.5 \pm 46.9$ & $0.46 \pm 0.02$ \\
\cline { 2 - 4 } & 1280 & $116.3 \pm 36.4$ & $0.74 \pm 0.05$ \\
\cline { 2 - 4 } & 1281 & $95.0 \pm 34.0$ & \\
\hline
\end{tabular}

Preliminary verifications had to be made before using the fibers for the pressure tests: The ramp speed was varied as well as the loading mechanism. The first was to confirm the stability of the fiber response to different loading speeds. With this, strain-hardening effects are ruled out. The latter differentiates between load-controlled loading and position-controlled loading. The conversion from load to pressure was calculated from the displacement of the stamp (in vertical direction, into the soft fibre). The area of contact between the stamp and the fibre was defined as that of two perpendicular cylinders (with one being much stiffer than the other). Indentation distance hence defined deformation of the fibre. Experienced load or pressure was then linked to the voltage detected in the LED-PT system by the time stamp.

In a highly-controlled system, a conversion from applied load to pressure can be done. For this, indentation depth and fibre diameter needs to be known. The final approximation was to not take lateral expansion into account (as if the Poisson's ratio was 0 ) and therefore use the width of the fibre at each depth value for the calculation of the contact area. The 
approximation should therefore also rather slightly underestimate contact area and result in slightly higher pressure values. As the sensor is used for evaluation of critical pressure values, a threshold would be reached earlier and hence not pose danger to a patient. Optimization could be done with the correct Poisson ratio and hence a better approximation of contact area. However, this would have to be adjusted for each polymer grade and, for even higher precision, for each fibre.

One method to verify the conversion is changing the way of loading the fibre. Two possibilities for this are available Figure S 1. Either the fibres are loaded in a load-controlled or in a position-controlled manner. For the first, the specified load is kept constant during the holding time while the second stays at the position it had when initially reaching the target load. With the fibres relaxing under the applied load, the first (Figure S 1 (top left)) then leads to further displacement of the stamp (blue axis). The second option (Figure $\mathbf{S} \mathbf{1}$ (bottom left)) shows constant displacement (blue axis as well, "Path into fibre") at the holding position, but decreasing load. The conversion of the two is then plotted on the right and shows the conversion including the standard deviation from the repetitions as well as the fibre diameter variation. From the mean value, the mean difference is calculated. Here, it amounts to $183 \mathrm{mmHg}$ at a level of $\sim 800 \mathrm{mmHg}$. With this, we hence result in an coefficient of variation of $2.3 \%$. 


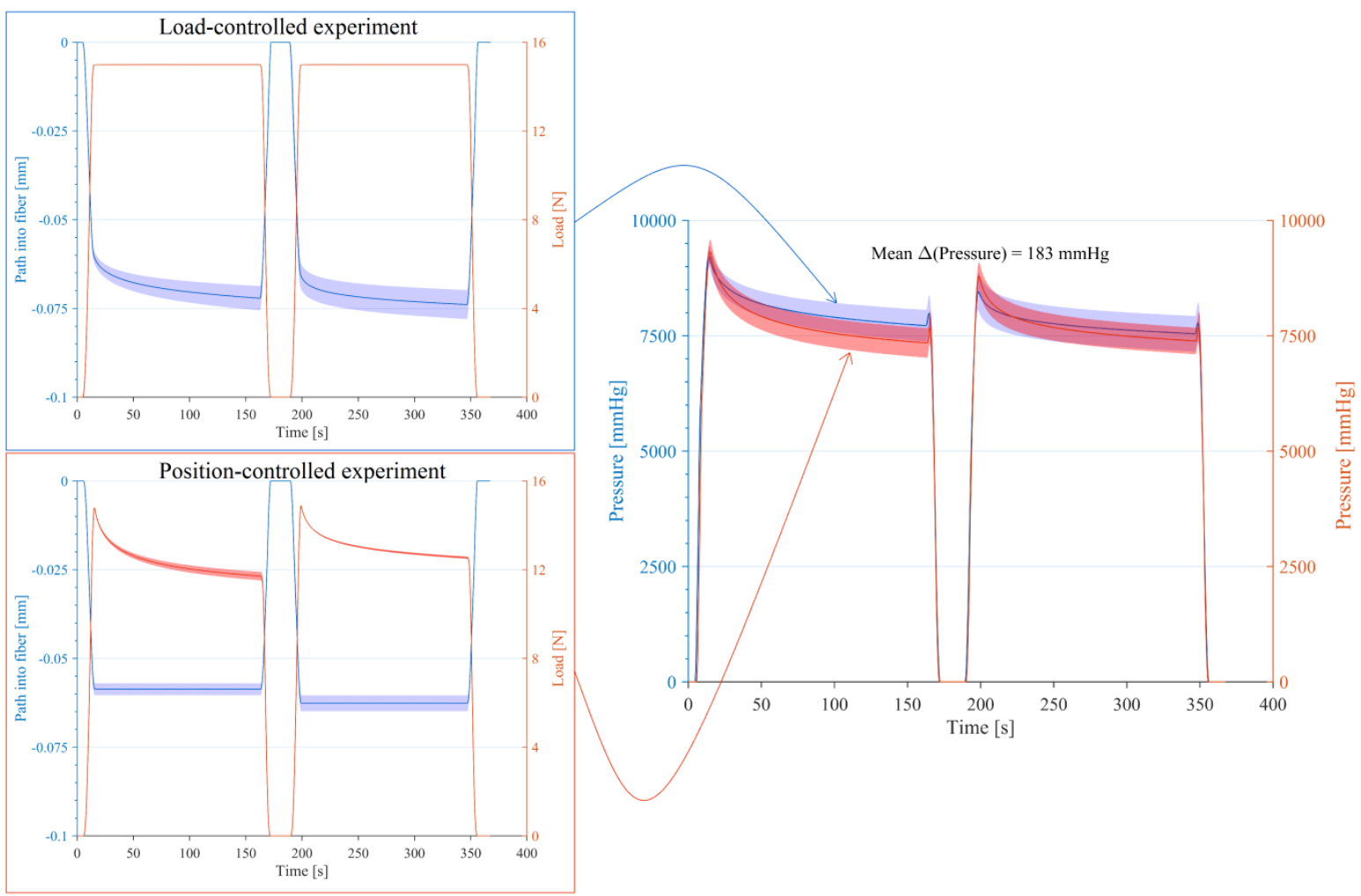

Figure $\mathrm{S}$ 1: (left) Two cycles of $15 \mathrm{~N}$ load on a pressure-sensitive fiber. The target load is controlled by either load value (top) or position (bottom), the responses of the fibers can be seen in blue. (right) Conversion of the leftern graphs into pressure [mmHg] showing the same result for both loading mechanisms. For all graphs, the mean value as well as the upper and lower standard deviation is plotted. 


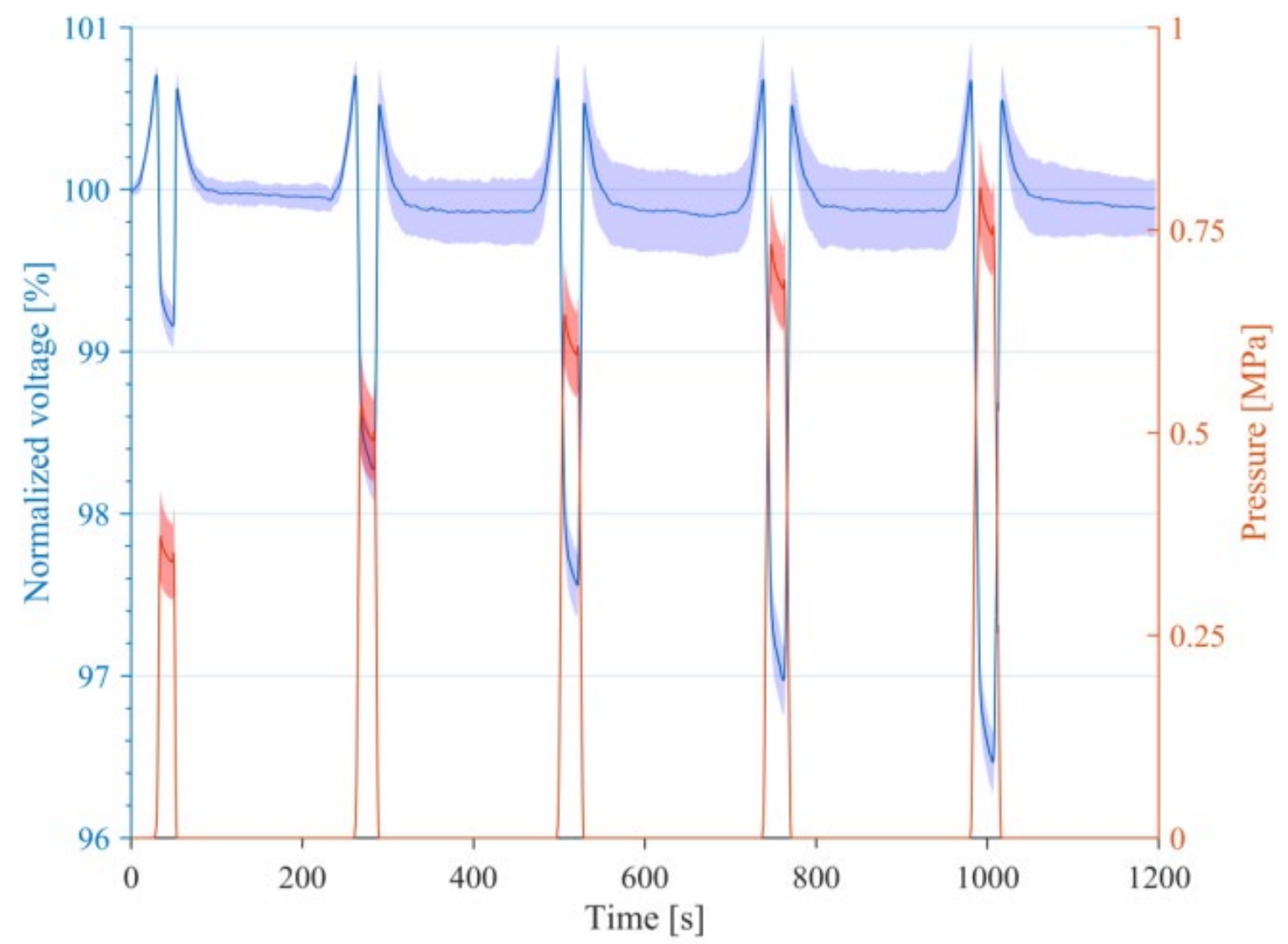

Figure S 2: Conversion of load cycles to pressure with the corresponding response of the fiber (ID-1263); the length of the fiber is $15 \mathrm{~cm}$; mean as well as upper and lower standard deviations are plotted for both applied pressure and normalized voltage. The fiber was increasingly loaded with $3,6,9,12$, and $15 \mathrm{~N}$. 
Table S 4: Runs used for the construction of the design of experiments with their corresponding levels and response values. Two extra runs are shown: one estimated by the model and one extrapolated from the model range; * Est $=$ estimated: The missing value, estimated by the model, is shown with $+-95 \%$ confidence level.

\begin{tabular}{|l|l|l|r|r|l|l|}
\hline$\#$ & $\begin{array}{l}\text { Extruder temperature } \\
{\left[{ }^{\circ} \mathrm{C}\right]}\end{array}$ & $\begin{array}{l}\text { Pull-off speed } \\
{[\mathrm{m} / \mathrm{min}]}\end{array}$ & \multicolumn{2}{l|}{ Levels } & Strain [\%] & $\begin{array}{l}\text { Tensile Modulus } \\
{[\mathrm{MPa}]}\end{array}$ \\
\hline 1260 & 200 & & & & & \\
\hline Est. $^{*}$ & $\mathbf{2 0 0}$ & 10 & -1 & -1 & $172 \pm 13$ & $79.5 \pm 4.6$ \\
\hline 1261 & 200 & $\mathbf{1 5}$ & $\mathbf{- 1}$ & $\mathbf{- 0 . 3 3}$ & $\mathbf{1 1 9} \pm \mathbf{4 9}$ & $\mathbf{1 0 5} \pm \mathbf{1 4}$ \\
\hline 1269 & 210 & 25 & -1 & +1 & $102 \pm 30$ & $89.5 \pm 8.6$ \\
\hline 1270 & 210 & 10 & 0 & -1 & $235 \pm 15$ & $71.5 \pm 3.5$ \\
\hline 1271 & 210 & 15 & 0 & -0.33 & $201 \pm 12$ & $83.5 \pm 5.4$ \\
\hline 1262 & 220 & 25 & 0 & +1 & $160 \pm 13$ & $76.7 \pm 4.8$ \\
\hline 1263 & 220 & 10 & +1 & -1 & $282 \pm 45$ & $56.7 \pm 3.7$ \\
\hline 1264 & 220 & 15 & +1 & -0.33 & $268 \pm 21$ & $57.5 \pm 4.3$ \\
\hline
\end{tabular}

Table S 5: Coefficients $\left(\beta_{i}\right)$ of the ANOVA model (eq. (1)) for the secant modulus. Significant terms $(\mathbf{p}<\mathbf{0 . 0 5})$ are marked in bold.

\begin{tabular}{|c|c|r|r|r|r|}
\hline Factor & Term & Coefficient & Std. Error & \multicolumn{1}{c|}{ t value } & \multicolumn{1}{|c|}{$\operatorname{Pr}(>|\mathbf{t}|)$} \\
\hline-- & $($ Intercept $)$ & $\mathbf{7 6 . 0 3 1 9}$ & $\mathbf{0 . 9 9 2 1}$ & $\mathbf{7 6 . 6 3 9}$ & $\mathbf{9 . 3 6 e - 1 3}$ \\
\hline \multirow{2}{*}{ Extruder T } & $\mathbf{x}_{1}$ & $\mathbf{- 2 2 . 5 2 5 3}$ & $\mathbf{1 . 9 2 4 6}$ & $\mathbf{- 1 1 . 7 0 4}$ & $\mathbf{2 . 5 9 e - 0 6}$ \\
\cline { 2 - 6 } & $\left(\mathrm{x}_{1}\right)^{2}$ & -1.4593 & 1.4836 & -0.984 & 0.3541 \\
\hline \multirow{2}{*}{$\begin{array}{c}\text { Pull-off } \\
\text { speed }\end{array}$} & $\mathbf{x}_{\mathbf{2}}$ & $\mathbf{3 . 8 8 6 0}$ & $\mathbf{1 . 2 4 7 7}$ & $\mathbf{3 . 1 1 4}$ & $\mathbf{0 . 0 1 4 3}$ \\
\cline { 2 - 6 } & $\left.\mathbf{( x}_{\mathbf{2}}\right)^{\mathbf{2}}$ & $\mathbf{- 8 . 2 5 0 4}$ & $\mathbf{2 . 0 8 5 3}$ & $\mathbf{- 3 . 9 5 6}$ & $\mathbf{0 . 0 0 4 2}$ \\
\hline \multirow{3}{*}{$\begin{array}{c}\text { Two-way } \\
\text { Interaction }\end{array}$} & $\mathrm{x}_{1}: \mathrm{x}_{2}$ & 1.3930 & 2.1981 & 0.634 & 0.5440 \\
\cline { 2 - 6 } & $\left(\mathrm{x}_{1}\right)^{2}: \mathrm{x}_{2}$ & 2.0740 & 2.1236 & 0.977 & 0.3573 \\
\cline { 2 - 6 } & $\mathrm{x}_{\mathbf{1}}:\left(\mathbf{x}_{\mathbf{2}}\right)^{\mathbf{2}}$ & $\mathbf{1 3 . 6 5 4 0}$ & $\mathbf{4 . 1 7 0 6}$ & $\mathbf{3 . 2 7 4}$ & $\mathbf{0 . 0 1 1 3}$ \\
\hline
\end{tabular}

Table S 6: Coefficients $\left(\beta_{i}\right)$ of the ANOVA model (eq. (1)) for the strain at break. Significant terms $(\mathbf{p}<\mathbf{0 . 0 5})$ are marked in bold.

\begin{tabular}{|c|c|r|r|r|r|}
\hline Factor & Term & Coefficient & \multicolumn{1}{c|}{ Std. Error } & \multicolumn{1}{c|}{ t value } & \multicolumn{1}{|c|}{$\operatorname{Pr}(>|\mathbf{t}|)$} \\
\hline & $($ Intercept $)$ & $\mathbf{1 9 2 . 9 2 8}$ & $\mathbf{3 . 5 1 5}$ & $\mathbf{5 4 . 8 8 6}$ & $\mathbf{1 . 3 5 e - 1 1}$ \\
\hline \multirow{2}{*}{ Extruder T } & $\mathrm{x}_{\mathbf{1}}$ & $\mathbf{8 3 . 8 3 9}$ & $\mathbf{6 . 8 1 9}$ & $\mathbf{1 2 . 2 9 4}$ & $\mathbf{1 . 7 8 e - 0 6}$ \\
\cline { 2 - 6 } & $\left(\mathrm{x}_{1}\right)^{2}$ & -6.667 & 5.257 & -1.268 & 0.240 \\
\hline \multirow{3}{*}{ Pull-off speed } & $\mathrm{x}_{2}$ & $\mathbf{- 5 3 . 5 0 3}$ & $\mathbf{4 . 4 2 1}$ & $\mathbf{- 1 2 . 1 0 2}$ & $\mathbf{2 . 0 1 e - 0 6}$ \\
\cline { 2 - 6 } & $\left(\mathrm{x}_{2}\right)^{2}$ & 6.524 & 7.389 & 0.883 & 0.403 \\
\hline \multirow{3}{*}{$\begin{array}{c}\text { Two-way } \\
\text { Interaction }\end{array}$} & $\mathrm{x}_{1}: \mathrm{x}_{2}$ & -11.399 & 7.788 & -1.464 & 0.181 \\
\cline { 2 - 6 } & $\left(\mathrm{x}_{1}\right)^{2}: \mathrm{x}_{2}$ & -1.363 & 7.524 & -0.181 & 0.861 \\
\cline { 2 - 6 } & $\mathrm{x}_{1}:\left(\mathrm{x}_{2}\right)^{2}$ & -24.747 & 14.777 & -1.675 & 0.133 \\
\hline
\end{tabular}


[1] M. Krehel, M. Schmid, R. Rossi, L. Boesel, G.-L. Bona, L. Scherer, An Optical FibreBased Sensor for Respiratory Monitoring, Sensors 14(7) (2014) 13088-13101.

[2] M. Krehel, M. Wolf, L.F. Boesel, R.M. Rossi, G.-L. Bona, L.J. Scherer, Development of a luminous textile for reflective pulse oximetry measurements, Biomedical Optics Express 5(8) (2014) 2537-2547.

[3] B.M. Quandt, L.J. Scherer, L.F. Boesel, M. Wolf, G.L. Bona, R.M. Rossi, BodyMonitoring and Health Supervision by Means of Optical Fiber-Based Sensing Systems in Medical Textiles, Adv. Healthc. Mater. 4(3) (2015) 330-355.

[4] R. Libanori, R.M. Erb, A. Reiser, H. Le Ferrand, M.J. Süess, R. Spolenak, A.R. Studart, Stretchable heterogeneous composites with extreme mechanical gradients, Nat. Commun. 3 (2012).

[5] F. Narbonneau, J. De Jonckheere, M. Jeanne, D. Kinet, J. Witt, K. Krebber, B. Paquet, A. Depré, L.T. D'Angelo, T. Thiel, R. Logier, OFSETH: optical technologies embedded in smart medical textile for continuous monitoring of respiratory motions under magnetic resonance imaging, in: J. Popp, W. Drexler, V.V. Tuchin, D.L. Matthews (Eds.) Biophotonics: Photonic Solutions for Better Health Care II, Brussels, Belgium, 2010, pp. 77151D-77151D-12.

[6] C. Yan, E. Ferraris, D. Reynaerts, A pressure sensing sheet based on optical fibre technology, Procedia Eng. 25(0) (2011) 495-498.

[7] M. Rothmaier, M.P. Luong, F. Clemens, Textile pressure sensor made of flexible plastic optical fibers, Sensors 8(7) (2008) 4318-4329.

[8] J.M. Yuan, M.A. El-Sherif, S. Khalil, J. Fairneny, Characterization of integrated fiber optic sensors in smart textiles, in: B. Culshaw, M.A. Marcus, J.P. Dakin, S.D. Crossley, H.E. Knee (Eds.) Industrial and Highway Sensors Technology, Spie-Int Soc Optical Engineering, Providence, RI, USA, 2003, pp. 197-206.

[9] W.C. Wang, W.R. Ledoux, B.J. Sangeorzan, P.G. Reinhall, A shear and plantar pressure sensor based on fiber-optic bend loss, J. Rehabil. Res. Dev. 42(3) (2005) 315-325.

[10] S. Poeggel, D. Tosi, D. Duraibabu, G. Leen, D. McGrath, E. Lewis, Optical fibre pressure sensors in medical applications, Sensors (Switzerland) 15(7) (2015) 17115-17148.

[11] A. Levi, M. Piovanelli, S. Furlan, B. Mazzolai, L. Beccai, Soft, transparent, electronic skin for distributed and multiple pressure sensing, Sensors (Switzerland) 13(5) (2013) 65786604.

[12] A. Massaro, F. Spano, P. Cazzato, C. La Tegola, R. Cingolani, A. Athanassiou, Robot tactile sensing: Gold nanocomposites as highly sensitive real-time optical pressure sensors, IEEE Rob Autom Mag 20(2) (2013) 82-90.

[13] B. Su, S. Gong, Z. Ma, L.W. Yap, W. Cheng, Mimosa-inspired design of a flexible pressure sensor with touch sensitivity, Small 11(16) (2015) 1886-1891.

[14] O. Ziemann, Polymer Optical fibers, in: T.F.M. Alexis Méndez (Ed.), Specialty optical fibers handbook, Academic Press2007.

[15] L. Bilro, N. Alberto, J.L. Pinto, R. Nogueira, Optical Sensors Based on Plastic Fibers, Sensors 12(9) (2012) 12184-12207.

[16] J. Zubia, J. Arrue, Plastic optical fibers: An introduction to their technological processes and applications, Opt. Fiber Technol. 7(2) (2001) 101-140.

[17] F.A. Reifler, R. Hufenus, M. Krehel, E. Zgraggen, R.M. Rossi, L.J. Scherer, Polymer optical fibers for textile applications - Bicomponent melt spinning from cyclic olefin polymer and structural characteristics revealed by wide angle X-ray diffraction, Polymer (United Kingdom) 55(22) (2014) 5695-5707. 
[18] W.R. White, L.L. Blyler Jr, R. Ratnagiri, M. Park, Manufacture of perfluorinated plastic optical fibers, Optical Fiber Communication Conference, OFC 2004, Los Angeles, CA, 2004, pp. 151-153.

[19] R.N. Srivastava, M.K. Dwivedi, A.K. Bhagat, S. Raj, R. Agarwal, A. Chandra, A nonrandomised, controlled clinical trial of an innovative device for negative pressure wound therapy of pressure ulcers in traumatic paraplegia patients, Int. Wound J. 13(3) (2016) 343348.

[20] J.G. Powers, C. Higham, K. Broussard, T.J. Phillips, Wound healing and treating wounds Chronic wound care and management, J. Am. Acad. Dermatol. 74(4) (2016) 607-625.

[21] R. Aissaoui, C. Kauffmann, J. Dansereau, J.A. de Guise, Analysis of pressure distribution at the body-seat interface in able-bodied and paraplegic subjects using a deformable active contour algorithm, Med. Eng. Phys. 23(6) (2001) 359-367.

[22] WHO, Ageing and life-course. accessed October, 2013).

[23] K. Heyer, K. Herberger, K. Protz, G. Glaeske, M. Augustin, Epidemiology of chronic wounds in Germany: Analysis of statutory health insurance data, Wound Repair Regen. 24(2) (2016) 434-442.

[24] A.F.T. Mak, M. Zhang, E.W.C. Tam, Biomechanics of Pressure Ulcer in Body Tissues Interacting with External Forces during Locomotion, in: M.L. Yarmush, J.S. Duncan, M.L. Gray (Eds.), Annual Review of Biomedical Engineering, Vol 12, Annual Reviews, Palo Alto, CA, USA, 2010, pp. 29-53.

[25] J.C. Ramella-Roman, T. Ho, D. Le, P. Ghassemi, T. Nguyen, A. Lichy, S. Groah, Monitoring the impact of pressure on the assessment of skin perfusion and oxygenation using a novel pressure device, Progress in Biomedical Optics and Imaging - Proceedings of SPIE, 2013.

[26] M. Makhsous, M. Priebe, J. Bankard, D. Rowles, M. Zeigler, D. Chen, F. Lin, Measuring tissue perfusion during pressure relief maneuvers: Insights into preventing pressure ulcers, Journal of Spinal Cord Medicine 30(5) (2007) 497-507.

[27] R. Hufenus, F.A. Reifler, K. Maniura-Weber, A. Spierings, M. Zinn, Biodegradable bicomponent fibers from renewable sources: Melt-spinning of poly(lactic acid) and poly[(3hydroxybutyrate)-co-(3-hydroxyvalerate)], Macromol. Mater. Eng. 297(1) (2012) 75-84. [28] D.C. Montgomery, Desing and analysis of experiments, John Wiley \& Sons, Singapore, 1991.

[29] L.F. Boesel, J.F. Mano, R.L. Reis, Optimization of the formulation and mechanical properties of starch based partially degradable bone cements, Journal of materials science. Materials in medicine 15(1) (2004) 73-83.

[30] R.C. Team, R: A Language and Environment for Statistical Computing, R Core Team, Vienna, Austria, 2012.

[31] J. Fox, The R commander: A basic-statistics graphical user interface to R, J Stat Softw 14(9) (2005).

[32] U. Grömping, Tutorial for designing experiments using the R package RcmdrPlugin.DoE Fachbereich II

Beuth Hochschule für Technik Berlin Berlin, 2011, p. 54.

[33] Thorlabs, Unmounted Longpass Colored Glass Filters.

$<$ http://www.thorlabs.de/newgrouppage9.cfm?objectgroup_id=999\&pn=FGL550\#3709>, 2016 (accessed February 24th.2016).

[34] E. Zgraggen, Fabrication and System Integration of Single-Mode Polymer Optical Waveguides, Electrical Engineering and Information Technologies, ETH Zurich, Zurich, Switzerland, 2014. 